\title{
Uji Sifat Fisik, Sun Protecting Factor, dan In Vivo ZnO Terdispersi dalam Sediaan Nanoemulgel
}

\author{
Dian E. Ermawati ${ }^{1,2 *}$, Adi Yugatama ${ }^{1,2}$ dan Wening Wulandari ${ }^{1}$ \\ ${ }^{1}$ Program Studi Farmasi, Fakultas Matematika dan Ilmu Pengetahuan Alam, Universitas Sebelas Maret \\ ${ }^{2}$ Grup Riset Teknologi Farmasi, Universitas Sebelas Maret \\ *email korespondensi : dianekae@staff.uns.ac.id
}

\begin{abstract}
Abstrak: Sediaan topikal yang memiliki kemampuan tabir surya semakin meningkat permintaannya seiring dengan kenaikan angka kejadian kanker kulit. Sunblock direkomendasikan pada rentang nilai sun protecting factor (SPF) 15-30. Seng oksida (ZnO) memiliki kemampuan untuk menghalau sinar ultraviolet (UV) dan mampu memberikan nilai SPF yang tinggi. Konsentrasi maksimum $\mathrm{ZnO}$ pada produk kosmetik sangat terbatas dan memiliki efek iritasi kulit apabila terlalu sering digunakan, sehingga perlu adanya inovasi teknologi formulasi untuk mengoptimalkan efek sunblock dari ZnO. Penelitian ini bertujuan untuk memformulasikan $\mathrm{ZnO}$ yang didispersikan ke dalam sediaan nano emulgel berbasis Carbopol. Serbuk $\mathrm{ZnO}$ akan didispersikan dalam formula self-nanoemulsifying drug delivery system yang terdiri dari minyak zaitun:Tween 80:propilen glikol yang selanjutnya didispersikan dalam polimer hidrogel Carbopol. Formula nanoemulgel dilakukan uji sifat fisik selama 42 hari meliputi: organoleptik, viskositas, daya sebar dan daya lekat; kemampuan SPF; serta uji kemampuan melindungi dari sinar UV B yang dilakukan pada kulit tikus wistar menggunakan skor eritema. Analisa statistik uji sifat fisik menggunakan taraf kepercayaan 95\% $(p=0,05)$. Hasil uji sifat fisik sediaan $\mathrm{ZnO}$ terdispersi dalam emulgel stabil selama penyimpanan suhu kamar dengan konsistensi semi padat, dan berwarna putih transparan. Karakteristik fisik meliputi daya sebar, daya lekat, dan viskositas memiliki perbedaan yang bermakna selama proses penyimpanan $(p<0,05)$. Hasil uji SPF menunjukkan bahwa sediaan $\mathrm{ZnO}$ terdispersi dalam nanoemulgel memiliki nilai SPF 25 (proteksi UV sedang) dan uji in vivo menunjukkan eritema sangat sedikit dengan skor 1 .
\end{abstract}

Kata kunci: ZnO; Nanoemulgel; SPF; Eritema kulit; Stabilitas fisik

Abstract. Physical Properties, Sun Protecting Factor, and In Vivo Test of ZnO-dispersed into Nanoemulgel. Topical preparations that have ability as ultraviolet (UV) protective are increasingly in demand along with the increase in the incidence of skin cancer. Sunblock with sun protecting factor ( $\mathrm{SPF}$ ) value of $15-30$ is recommended i.e. zinc oxide $(\mathrm{ZnO})$. $\mathrm{ZnO}$ is able to block the UV light better than $\mathrm{TiO}_{2}$. The maximum concentration of $\mathrm{ZnO}$ in cosmetic products is limited and it has an irritation effect when it is used extensively. Therefore, an alternative way should be developed in order to optimize the sunblock effect of $\mathrm{ZnO}$. This study purposed to formulate $\mathrm{ZnO}$ dispersed into Carbopol-based nanoemulgel. $\mathrm{ZnO}$ powder was dispersed into self-nano emulsion formulation consisting of olive oil:Tween 80:propylene glycol followed by dispersion in Carbopol. All formulations were tested for physical properties for 42 days including: organoleptic, viscosity, spreadibility, adhesion, SPF value, and the ability to protect against UV B rays using animal model according to erythema scores. The data was compared statistically along with confidence level of $95 \%(\mathrm{p}=0.05)$. $\mathrm{ZnO}$ nanoemulgel physical properties test results were stable during room temperature storage with 
a semi-solid consistency, and white transparent color. Physical characteristics including spreadability, adhesion, and viscosity have significant differences every week $(p<0.05)$. The SPF test results showed that the ZnO nanoemulgel had the SPF value of 25 (moderate UV protection) and the in vivo test showed low erythema with score of 1.

Keywords: ZnO; Nanoemulgel; SPF; Erythema skin; Physical stability

\section{Pendahuluan}

Angka kejadian kanker kulit di Indonesia semakin meningkat, sehingga diperlukan produk yang mampu menangkal pengaruh buruk radiasi sinar ultraviolet (UV) salah satunya sediaan topikal tabir surya. Senyawa tabir surya dengan nilai SPF lebih dari 30 yaitu seng oksida $(\mathrm{ZnO})$ dan titanium oksida. $\mathrm{ZnO}$ mampu menghalangi secara fisik spektrum dan kuantum sinar ultraviolet lebih baik dibandingkan $\mathrm{TiO} 2$. Konsentrasi maksimum $\mathrm{ZnO}$ pada produk kosmetik adalah 10\%, namun memiliki efek iritasi kulit apabila terlalu sering digunakan, sehingga perlu adanya inovasi teknologi formulasi untuk menurunkan konsentrasi $\mathrm{ZnO}$ dalam sediaan tabir surya namun tetap memiliki kemampuan UV protective yang optimal.

SNEDDS merupakan campuran isotropik dari minyak, surfaktan, dan ko-surfaktan. Pemilihan fase minyak yang sesuai untuk formulasi SNEDDS adalah minyak yang mengandung banyak asam lemak rantai menengah dan panjang (Patel et al., 2011). Minyak zaitun mengandung asam oleat (80\%), sehingga memiliki kemampuan self-emulsifying yang tinggi dan kapasitas drug loading yang besar (Nugraheni, 2012). Tween 80 dipilih sebagai surfaktan karena bersifat hidrofilik dengan nilai HLB 15 dan sediaan SNEDDS yang dihasilkan memiliki persentase transmitan di atas 80\% (Diba et al., 2014). Propilen glikol dipilih sebagai ko-surfaktan karena mampu menurunkan tegangan antar muka minyak dalam air dan membantu kerja surfaktan (Patel et al., 2011). Nurdianti et al., (2017) menyatakan pemilihan surfaktan dan ko-surfaktan dilakukan dengan kombinasi 1:1; 2:1; 4:1; 6:1; 8:1; 1:8; 1:6; 1:4 dan 1:2 untuk menghasilkan larutan yang jernih.

Penelitian sebelumnya telah dilakukan yaitu pada perbandingan 8:1 Tween 80 dan propilen glikol mampu menghasilkan globul-globul emulsi yang terdispersi baik dalam medium air. Kombinasi surfaktan (Tween 80) dan fase minyak yang telah dilakukan uji kompatibilitas sebelumnya dapat menampung $\mathrm{ZnO} 3,2 \mu \mathrm{g} / \mathrm{mL}$ (Wulandari, 2019). Formula SNEDDS yang terdiri dari 9,1\% minyak, $81 \%$ surfaktan, dan 9,9\% ko-surfaktan memiliki loading dose $\mathrm{ZnO} 2,0 \mathrm{mg} / \mathrm{g}$ sistem (Wulandari, 2019). SNEDDS terinkorporasi $\mathrm{ZnO}$ selanjutnya didispersikan dalam matrik hidrogel dimaksudkan untuk membentuk dispersi koloid yaitu nanoemulsi $\mathrm{ZnO}$ dalam hidrogel. Campuran isotropik minyak zaitun-Tween 80propilen glikol yang mendispersikan $\mathrm{ZnO}$ menjadi partikel yang lebih kecil akan membentuk 
self-emulsifying ketika bertemu dengan air yang disini adalah matriks hidrogel. Hidrogel memiliki syarat utama berbentuk semi padat, jernih, stabil, transparan, dan mengandung zat aktif yang terdispersi dalam suatu sistem koloid, oleh karena itu, dibuat dalam sediaan nanoemulgel $\mathrm{ZnO}$ agar mudah diaplikasikan pada kulit, memiliki penampilan sediaan yang jernih dan elegan, setelah kering meninggalkan film tembus pandang, mudah dicuci dengan air, dan kemampuan penyebarannya baik (Kaur dan Guleri, 2013). Sediaan ZnO basis nano emulgel berbasis polimer Carbopol belum pernah dilakukan sebelumnya.

Stabilitas nanoemulgel $\mathrm{ZnO}$ selama penyimpanan 28 hari pada suhu ruang digunakan untuk memastikan bahwa partikel $\mathrm{ZnO}$ stabil dalam matriks pembawanya. Stabilitas fisika dapat diartikan suatu formula sediaan kosmetik tidak berubah secara total sepanjang umur simpannya dan belum mengalami perubahan total dalam penampilan, sifat organoleptik, konsistensi, caking/coalescence, mencair, dan berubahnya ukuran partikel. Hal ini akan menyebabkan kehilangan pharmaceutical elegance, keseragaman kandungan zat aktif, dan berubahnya profil pelepasan zat aktif. Penelitian ini bertujuan untuk memformulasikan sediaan $\mathrm{ZnO}$ yang didispersikan pada nanoemulgel berbasis polimer Carbopol untuk peningkatan potensi sunblock dari $\mathrm{ZnO}$.

\section{Bahan dan Metode}

$\mathrm{ZnO}$ (Zochem, USA), Olive oil (Batch: MM-180717-KO), VCO (foodgrade), tween 80 (Ex German Batch: 3111 Lot.916) dan PEG 400 (X17556), propilen glikol (DOW Chemical Pacific, Singapore), gliserin (DOW Chemical Pacific, Singapore), karbopol 940 (Changcun Petrochemical, Taiwan), trietanolamin (Changcun Petrochemical, Taiwan), (nipagin (Batch: 0119115-E), aquabidest (IKA). Semua bahan diperoleh dari pemasok lokal (Bratachem, Surakarta, Indonesia). Kosmetik gel SPF 17 (Merek X) dibeli dari pasaran untuk kontrol positif.

\subsection{Formulasi nanoemulgel $\mathrm{ZnO}$}

Komponen SNEDDS yang terdiri dari 9,1\% minyak zaitun, 81\% Tween 80, dan 9,9\% PEG 400 dengan bobot total 5,0 g ditimbang dan dicampur, kemudian ditambahkan $\mathrm{ZnO}$ dengan dosis $10 \mathrm{mg} / \mathrm{g}$ sistem dimasukkan dalam flakon. Campuran dihomogenkan dengan vortex selama 1,0 menit dan disonikasi selama 10 menit. Campuran SNEDDS kemudian diinkubasi dengan waterbath pada suhu $45^{\circ} \mathrm{C}$ selama 15 menit hingga homogen. SNEDDS disimpan di suhu ruang selama proses karakterisasi (Savale, 2015). Pengujian ukuran partikel dan zeta potensial dilakukan dengan mengambil $100 \mu \mathrm{L}$ SNEDDS lalu dilarutkan dalam $5 \mathrm{~mL}$ akuades, gojok perlahan, selanjutnya dianalisa menggunakan alat particle size analyzer (Horiba SZ-100; Worcestershire, UK). 
Hidrogel yang formulanya tersaji pada Tabel 1 dibuat dengan mengembangkan Carbopol dalam air hangat hingga terdispersi sempurna dibantu dengan pengadukan. TEA ditambahkan sebagian dan diaduk hingga terbentuk masa hidrogel yang transparan. Gliserin ditambahkan, dan nipagin yang sudah dilarutkan dalam propilen glikol kemudian diaduk sampai homogen. TEA dan aquadest kemudian diaduk dengan kecepatan konstan sampai homogen (Panjaitan et al., 2013). SNEDDS ZnO sejumlah 5,0 g didispersikan dalam basis hidrogel dengan menuangkan larutan SNEDDS secara perlahan ke dalam $95 \mathrm{~g}$ hidrogel sambil diaduk dengan homogenizer kecepatan rendah samapai homogen.

Tabel 1. Formula (F) basis hidrogel dengan variasi konsentrasi gelling agent Carbopol 940

\begin{tabular}{lcccc}
\hline \multicolumn{1}{c}{ Nama Bahan } & FI $(\%)$ & FII $(\%)$ & FIII $(\%)$ & FIV $(\%)$ \\
\hline Carbopol 940 & 0,50 & 0,40 & 0,35 & 0,30 \\
Gliserin & 10,07 & 10,08 & 10,09 & 10,09 \\
Propilen glikol & 5,04 & 5,04 & 5,04 & 5,05 \\
Nipagin & 0,05 & 0,05 & 0,05 & 0,05 \\
Trietanolamin & 3,78 & 3,78 & 3,78 & 3,78 \\
Akuades & 80,56 & 80,65 & 80,69 & 80,73 \\
\hline
\end{tabular}

\subsection{Pengujian sifat fisik nanoemulgel $\mathrm{ZnO}$}

Sediaan nanoemulgel $\mathrm{ZnO}$ disimpan pada suhu kamar $25 \pm 2{ }^{\circ} \mathrm{C}$ dengan $\mathrm{RH} 60 \%$ selama kurun waktu 28 hari. Pengujian dilakukan pada hari pertama dan hari ke-28 yaitu meliputi organoleptis, homogenitas, daya sebar, daya lekat,dan viskositas.

\subsubsection{Uji organoleptis}

Uji organoleptis dilakukan dengan pengamatan secara visual menggunakan panca indera untuk mendiskripsikan bentuk, warna, dan bau dari sediaan $\mathrm{ZnO}$ terdispersi dalam nanoemulgel.

\subsubsection{Uji homogenitas}

Uji homogenitas dilakukan dengan mengoleskan 0,5 g gel pada sekeping kaca objek dan dilihat dibawah mikroskop. Sediaan harus menunjukkan susunan yang homogen dan tidak ada butiran kasar.

\subsubsection{Uji daya sebar}

Uji daya sebar dilakukan dengan menimbang gel sebanyak 0,5 $\mathrm{g}$ dan diberi beban $150 \mathrm{~g}$ selama 1 menit (Kaur et al., 2010). Daya sebar diukur melalui diameter yang sediaan yang terbentuk dengan jangka sorong (ketelitian 0,01 mm, Mituyoto; Tokyo, Jepang).

\subsubsection{Uji daya lekat}

Uji daya lekat dilakukan dengan meletakkan 0,5 g hidrogel diatas objek glass kemudian ditutup dengan objek glass lagi dan diberikan beban 1,0 kg selama 5 menit. Beban seberat 80 g dilepaskan, sehingga menarik objek glass bagian bawah. Waktu yang diperlukan hingga 
kedua objek glass terlepas dicatat sebagai daya lekat (Niyogi et al., 2012).

\subsubsection{Uji viskositas}

Uji viskositas dilakukan dengan alat viskometer RION, sampel gel dimasukkan ke dalam beaker glass dan diletakkan di bawah gantungan spindel, kemudian spindel diturunkan hingga batas tercelup ke dalam sediaan $\mathrm{ZnO}$ terdispersi dalam nanoemulgel . Rotor dinyalakan dan diamati jarum merah pada skala, kemudian dibaca angka yang ditunjukkan oleh jarum tersebut (Sayuti, 2015).

\subsection{Uji aktivitas sediaan secara in vitro dan in vivo}

Sebanyak 100 mg gel diencerkan menggunakan akuades hingga 10,0 mL, kemudian diambil 1,0 mL dan dimasukkan dalam labu ukur 10,0 mL ditambah akuadest sampai batas. Larutan disaring menggunakan kertas Whattman No.1 selanjutnya dilakukan pengukuran serapan menggunakan spektrofotometer UV/Vis (Thermo Genesys-10; Whaltham, MA) pada rentang panjang gelombang 320-290 nm setiap interval $5 \mathrm{~nm}$ dan blanko yang digunakan yaitu akuades. Hasil serapan yang didapat pada masing masing dosis dicatat dan dihitung nilai SPF (Yulianti et al., 2016). Sebagai pembanding diukur pula nilai absorbansi basis nanoemulgel tanpa $\mathrm{ZnO}$, dan produk dengan nilai SPF 17.

Pengujian in vivo menggunakan hewan uji dilakukan berdasarkan izin Komite Etik Penelitian Fakultas Kedokteran Universitas Muhammadiyah Surakarta No.1705/A.01/KEPKFKUMS/IX/2018 untuk melindungi subjek penelitian atau responden. Hewan uji yang digunakan adalah tikus jantan galur wistar dengan berat badan $200 \mathrm{~g}$ dan berusia 2-3 bulan dengan masing-masing kelompok percobaan tiga ekor tikus. Empat kelompok hewan uji diberikan perlakuan, yaitu kontrol negatif (tidak diolesi tabir surya), kontrol positif (diolesi gel tabir surya yang ada dipasaran) dan perlakuan (diolesi $\mathrm{ZnO}$ terdispersi dalam emulgel). Punggung tikus dicukur dengan luas $3 \times 4 \mathrm{~cm}$ dan diolesi bahan uji. Kontak bahan uji dengan punggung tikus yang telah dicukur yaitu selama 1 jam kemudian diradiasi dengan lampu exoterra selama 24 jam. Setelah 24 jam luas eritema yang terjadi dihitung dengan menggunakan jangka sorong (Wulandari, 2017).

\subsection{Analisa Data}

Hasil evaluasi sifat fisik $\mathrm{ZnO}$ terdispersi dalam emulgel meliputi viskositas, daya sebar, dan daya lekat dianalisis dengan One-Way ANOVA dan dilanjutkan uji Post-Hoc LSD. Hasil analisis tidak berbeda signifikan dengan $p$-value $>0,05$. Nilai kemampuan tabir surya dianalisis menggunakan uji One-Way ANOVA dan dilanjutkan uji Post-Hoc LSD kemudian dibandingkan dengan tabel kemampuan tabir surya secara in vitro dan in vivo. 


\section{Hasil dan Pembahasan}

Hasil dari optimasi formula SNEDDS menunjukkan perbandingan 1:9:1 memiliki persen transmitan mendekati blanko yaitu 100,38\%. Komposisi surfaktan dan ko-surfaktan akan memberikan efisiensi emulsifikasi yang baik pada konsentrasi surfaktan $>75 \%$ dan emulsifikasi secara spontan tidak efektif apabila konsentrasi surfaktan $<50 \%$ (Mahmoud et al., 2013). Hasil karakterisasi formula optimal menunjukkan nilai transmitan 92,16 $\pm 0,09 \%$; pH 7,31 $\pm 0,04$; ukuran partikel 152,7 nm; indeks polidisperse 0,58; potensial zeta $-28,5 \mathrm{mV}$. Nilai PI pada pengukuran partikel digunakan untuk menggambarkan homogenitas partikel nanoemulsi yang memiliki rentang 0,0 sampai 1,0 (Pratiwi et al., 2017). Ukuran partikel yang kecil disertai dengan nilai potensial zeta yang besar dapat meningkatkan stabilitas nanoemulsi secara kinetik. Hal ini berkaitan dengan efek gerak Brown yang semakin meningkat ketika ukuran partikel semakin kecil, sehingga kecenderungan terjadinya agregasi berkurang dan stabilitas emulsi meningkat (Jafari and McClements, 2018). Hasil nilai potensial zeta dari formula optimal SNEDDS yaitu $-28,5 \mathrm{mV}$. Rentang nilai potensial zeta untuk dapat mempertahankan stabilitas yaitu kurang dari $-30 \mathrm{mV}$ atau lebih dari +30 dimana pada rentang tersebut mampu memberikan muatan permukaan partikel yang signifikan untuk terjadinya tolak-menolak. Jika semua partikel memiliki nilai potensial zeta negatif yang besar, maka partikel tersebut memiliki gaya tolak menolak yang semakin besar untuk mencegah terjadinya agregat dan timbulnya fase pemisahan (Jafari \& McClements, 2018).

Pembuatan hidrogel dilakukan dengan mengoptimasi basis hidrogel yaitu Carbopol 940 sebagai gelling agent. Carbopol 940 dipilih untuk dioptimasi karena memiliki viskositas yang tinggi dan penampakan yang lebih jernih dibandingkan dengan Carbopol 934 (Rowe et al., 2009). Penambahan TEA (trietanolamin) dengan konsentrasi $1 \%$ dilakukan untuk menetralkan sifat asam dari Carbopol 940, sedangkan penambahan gliserin dan propilen glikol digunakan sebagai humektan (pelembab sediaan) dan emollient (menjaga kehilangan air dari sediaan). Nipagin sebagai pengawet ditambahkan dengan melarutkan ke dalam propilen glikol karena memiliki kelarutan dalam lima bagian propilen glikol. Uji pH dilakukan untuk melihat keasaman sediaan hidrogel, sehingga tidak menimbulkan iritasi pada kulit. Hasil uji pH dari empat formula menunjukkan semua formula memenuhi syarat sediaan hidrogel. Nilai pH yang dipersyaratkan untuk sediaan tabir surya berdasarkan SNI 16-49521998 yaitu berkisar antara 4- 7,5 (Gurning, 2016). Uji daya sebar dilakukan untuk menjamin tersebarnya hidrogel saat diaplikasikan ke kulit karena basis merupakan faktor yang menentukan kecepatan pelepasan obat yang nantinya akan mempengaruhi khasiat obat. Daya sebar merupakan bagian dari psikoreologi yang dapat dijadikan parameter acceptabilitas 
(Basha et al., 2011). Hasil uji daya sebar yang memenuhi syarat yaitu F3 (Carbopol 0,07 gram) dengan diameter 5,4 cm. Daya sebar yang dipersyaratkan untuk sediaan hidrogel yaitu 5-7 cm (Kaur et al., 2010). Pengujian viskositas dilakukan untuk mengetahui kekentalan sediaan hidrogel. Hasil uji viskositas yang memenuhi syarat yaitu F2 dan F3 dengan kekentalan 100 dan 180 dPas. Viskositas hydrogel yang baik berada pada rentang 50-1000 dPas, dengan viskositas optimal 200 dPas (Nurahmanto et al., 2017) (Tabel 1), sehingga dipilih F3 karena memenuhi syarat viskositas dan daya sebar yang optimum.

\subsection{Uji sifat fisik $\mathrm{ZnO}$ terdispersi dalam nanoemulgel}

Viskositas merupakan tahanan dari suatu cairan yang mengalir, semakin besar tahanan maka semakin besar pula viskositasnya. Hasil rata-rata uji daya lekat pada minggu ke-0 sebesar 376,66 $\pm 5,77$ dPas, minggu ke- 2 sebesar $360 \pm 17,32$ dPas, minggu ke-4 sebesar $316,67 \pm 15,27$ dPas (Gambar 1a). Nilai viskositas hidrogel yang baik berada pada rentang 501000 dPas, dengan viskositas optimal 200 dPas (Nurahmanto et al., 2017). Hasil tersebut menunjukkan bahwa perbedaan viskositas yang signifikan terjadi pada minggu ke-0 dengan minggu ke-4, minggu ke-1 dengan minggu ke-4, dan minggu ke-2 dengan minggu ke-4, sehingga dapat diketahui stabilitas $\mathrm{ZnO}$ terdispersi dalam nanoemulgel selama masa penyimpanan 4 minggu mengalami penurunan viskositas dimungkinan karena basis hidrogel menurun konsistensinya pada suhu kamar.

Daya sebar yang baik untuk sediaan hidrogel yaitu 5-7 cm (Kaur et al., 2010). Semakin besar daya sebar sediaan hidrogel yang diberikan, maka kemampuan zat aktif untuk menyebar dan kontak dengan kulit semakin luas (Niazi, 2004). Hasil rata-rata uji daya sebar (Gambar 1b) pada minggu ke-0 sebesar 5,38 $\pm 0,10 \mathrm{~cm}$, minggu ke-2 sebesar 5,73 $\pm 0,32 \mathrm{~cm}$, minggu ke-

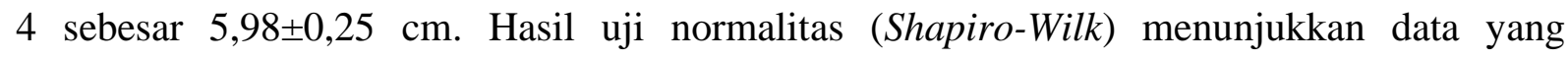
terdistribusi normal dengan $p$-value $>0,05$ dan hasil uji homogenitas menunjukkan data yang homogen dengan $p$-value $>0,05$, sehingga syarat uji One-Way ANOVA terpenuhi. Hasil OneWay ANOVA diperoleh nilai signifikansi p-value <0,05 yang menunjukkan paling tidak terdapat perbedaan daya sebar yang signifikan pada dua kelompok minggu. Analisis lanjutan yang dilakukan yaitu uji Post Hoc Least Significance Different (LSD) bertujuan untuk mengetahui kelompok minggu manakah yang memiliki perbedaan signifikan. Hasil tersebut menunjukkan bahwa perbedaan daya sebar yang signifikan terjadi pada minggu ke-0 dengan minggu ke-4 dan minggu ke-2 dengan minggu ke-0. Daya sebar yang semakin meningkat seiring dengan menurunya viskositas matrik hidrogel.

Pengujian daya lekat (Gambar 1c) dilakukan untuk mengetahui kemampuan gel dalam melapisi permukaan kulit secara kedap, tidak menyumbat pori-pori serta tidak menyumbat 
fungsi fisiologis kulit. Hasil rata-rata uji daya lekat pada minggu ke- 0 sebesar 5,13 $\pm 0,04$ detik, minggu ke- 2 sebesar 5,08 \pm 0,05 detik, minggu ke-4 sebesar 5,02 \pm 0,03 detik, dan minggu ke-6 sebesar 4,94 $\pm 0,03$ detik. Semakin lama sediaan melekat pada kulit maka semakin lama $\mathrm{ZnO}$ tinggal pada pemukaan kulit untuk melindungi kulit dari bahaya sinar, sehingga semakin efektif dalam penggunaannya (Suena et al., 2017).

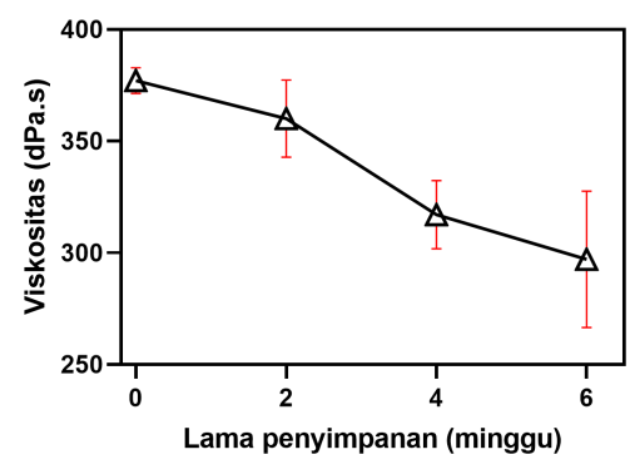

a
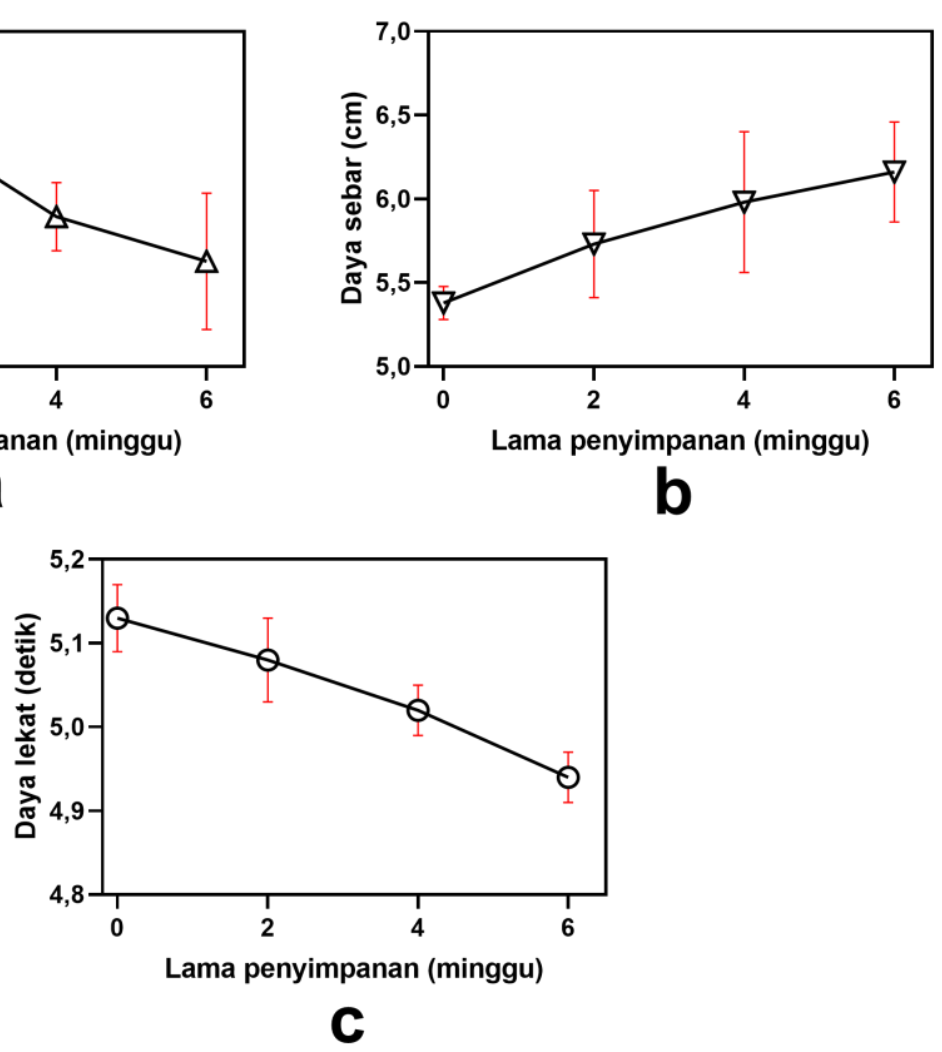

Gambar 1. Profil perubahan viskositas (a), daya sebar (b), dan daya lekat (c) selama 6 minggu penyimpanan pada uji sifat fisik $\mathrm{ZnO}$ terdispersi dalam nanoemulgel

\subsection{Uji in vitro sediaan $\mathrm{ZnO}$ terdispersi dalam nanoemulgel}

Metode yang digunakan untuk menentukan nilai SPF yaitu metode LMbanga, 2014. Hasil yang didapatkan dari uji in vitro yaitu SNEDDS terinkorporasi ZnO memiliki nilai SPF 16,40. ZnO terdispersi dalam emulgel memiliki nilai SPF 24,54. Peningkatan nilai SPF ZnO terdispersi dalam emulgel dikarenakan terbentuk nanoemulsi antara SNEDDS dengan basis hydrogel dan efek ZnO. Pengukuran nilai SPF juga dilakukan pada sistem SNEDDS dan basis hidrogel untuk mengetahui pengaruh sistem SNEDDS dan basis hidrogel terhadap nilai SPF $\mathrm{ZnO}$ terdispersi dalam nanoemulgel. Komposisi SNEDDS (olive oil:Tween 80:propilen glikol) memiliki nilai SPF 4,78, sedangkan basis hidrogel (Carbopol, trietanolamin, propilen glikol, nipagin, dan gliserin) memiliki nilai SPF 3,07. Hasil pengukuran absorbansi menunjukkan nilai SPF sistem SNEDDS dan basis hidrogel memiliki pengaruh terhadap peningkatan nilai SPF ZnO terdispersi dalam nanoemulgel. Hasil ini menunjukkan bahwa 
pembuatan sediaan $\mathrm{ZnO}$ terdispersi dalam nanoemulgel memberikan aktivitas yang lebih efektif sebagai tabir surya dibandingkan dengan pembuatan hidrogel $\mathrm{ZnO}$ yang memiliki nilai SPF 8,32 (Tabel 2). Perhitungan nilai SPF juga dilakukan pada sediaan emulgel di pasaran dengan klaim SPF 17 dengan tujuan untuk melihat validasi metode yang digunakan. Hasil yang didapatkan dari perhitungan menggunakan metode (Lmbanga, 2014) yaitu memiliki nilai SPF 15,28. Hasil penentuan nilai SPF tidak berbeda jauh dengan yang tertulis dilabel kemasan. $\mathrm{ZnO}$ terdispersi dalam nanoemulgel memiliki nilai SPF 24,54 maka apabila digunakan akan bertahan selama 30 x 24,54 menit $=736,20$ menit sama dengan 12 jam 27 menit di bawah paparan sinar matahari. Formula SNEDDS terinkorporasi ZnO memiliki nilai SPF 16,40 yang berarti akan melindungi dari paparan UV B bertahan selama 8 jam 20 menit.

Tabel 2. Hasil uji in vitro yaitu nilai SPF dalam pelarut air menggunakan metode spektrofotometri UV VIS

\begin{tabular}{lcc}
\hline Sampel & Nilai SPF \pm SE & Kemampuan $\boldsymbol{U}$ Protection \\
\hline SNEDDS kosong & $4,78 \pm 0,04$ & Minimum \\
ZnO terdispersi SNEDDS & $16,40 \pm 0,11$ & Medium \\
Basis hidrogel & $3,07 \pm 0,03$ & Minimum \\
ZnO terdispersi nanoemulgel & $25,0 \pm 0,09$ & Medium \\
Hidrogel ZnO & $8,32 \pm 0,02$ & Minimum \\
Brand product gel SPF 17 & $15,28 \pm 0,01$ & Medium \\
\hline
\end{tabular}

\subsection{Uji in vivo formula optimum $\mathrm{ZnO}$ terdispersi dalam nanoemulgel}

Pengujian aktivitas tabir surya secara in vivo dilakukan menggunakan hewan uji tikus putih dengan tiga kelompok perlakuan, yaitu kontrol positif, kontrol negatif, dan $\mathrm{ZnO}$ terdispersi dalam nanoemulgel. Kontrol positif yang digunakan yaitu sediaan gel tabir surya di pasaran dengan nilai SPF 17 untuk membandingkan $\mathrm{ZnO}$ terdispersi dalam nanoemulgel. Berdasarkan waktu yang telah ditentukan untuk mengamati efek tabir surya yang dilakukan pada hewan uji tikus putih, dibutuhkan waktu 24 jam agar dapat melihat efek dari kontrol yang diberikan (Wulandari et al., 2017). Kelompok kontrol negatif memiliki nilai eritema 3 (eritema moderat) dimana punggung tikus membentuk kerak dan merah menyala karena tidak ada perlakuan atau perlindungan tabir surya (Gambar 2).

Kelompok kontrol positif digunakan sediaan gel di pasaran dengan nilai SPF 17 memiliki nilai eritema 2 (eritema berbatas jelas) yang menunjukkan gel dengan SPF 17 belum mampu melindungi punggung tikus dari sinar UV. Kelompok perlakuan diberikan sediaan SNEDDS terinkorporasi $\mathrm{ZnO}$ dan $\mathrm{ZnO}$ terdispersi dalam nanoemulgel yang memberikan hasil tidak terjadi eritema setelah dibuat dalam sediaan $\mathrm{ZnO}$ terdispersi dalam nanoemulgel yang mengindikasikan mampu melindungi kulit dari sinar UV B (Tabel 3). Hasil 
tersebut menunjukkan bahwa antar kelompok memiliki perbedaan nilai eritema yang signifikan, sehingga dapat diketahui perbedaan perlakuan pada hewan uji.

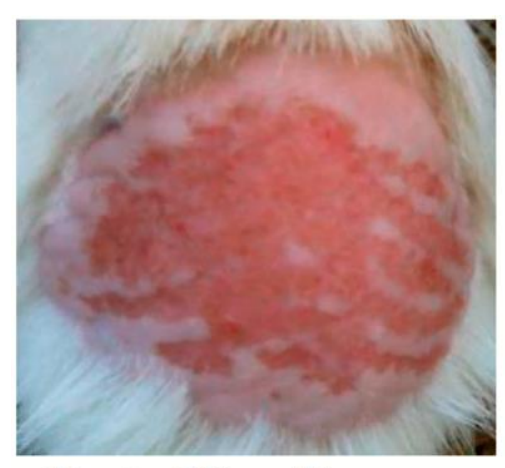

Kontrol Negatif

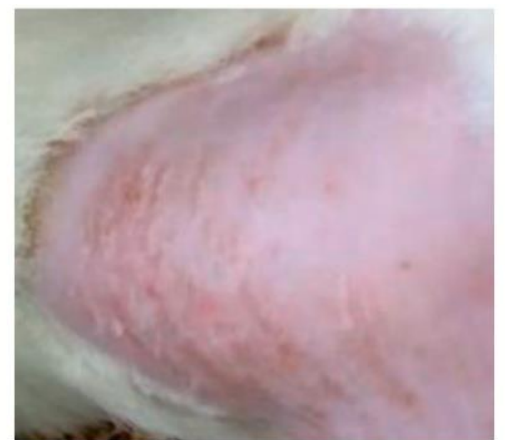

Brand Product Gel SF 17

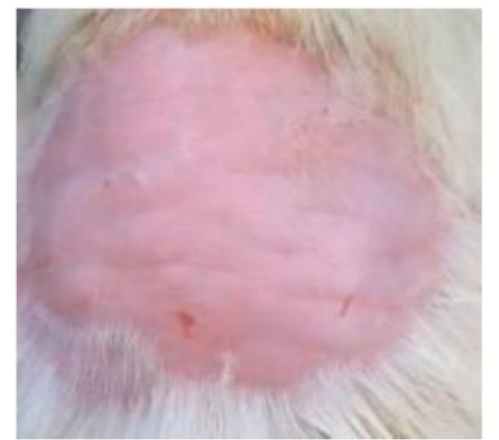

ZnO terdispersi nanoemulgel

Gambar 2. Hasil pengujian eritema $\mathrm{ZnO}$ terdispersi dalam nanoemulgel pada punggung tikus.

Tabel 3. Hasil uji in vivo berdasarkan erithema score pada kulit punggung tikus jantan galur Wistar

\begin{tabular}{lccc}
\hline \multicolumn{1}{c}{ Kelompok Uji } & $\begin{array}{c}\text { Diameter area } \\
\text { eritema }(\mathbf{m m}) \pm \text { SE }\end{array}$ & $\begin{array}{c}\text { Nilai } \\
\text { eritema }\end{array}$ & $\begin{array}{c}\text { Kesimpulan } \\
\text { Kontrol negatif }\end{array}$ \\
$32,33 \pm 0,14$ & 3 & Medium-tinggi \\
Produk pembanding (SPF 17) & $26,51 \pm 0,26$ & 2 & Medium \\
ZnO terdispersi dalam nanoemulgel & $1,74 \pm 0,07$ & 1 & Minimum \\
\hline
\end{tabular}

\section{Kesimpulan}

Hasil uji sifat fisik $\mathrm{ZnO}$ terdispersi dalam nanoemulgel selama penyimpanan selama 28 hari menunjukkan hasil cukup stabil selama 28 hari penyimpanan meliputi daya sebar, daya lekat, dan viskositas, walaupun hasil pengujian memiliki perbedaan signifikan tiap minggunya $(\mathrm{p}<0,05)$, namun masih dalam rentang memenuhi persyaratan sesuai standar sediaan gel yaitu

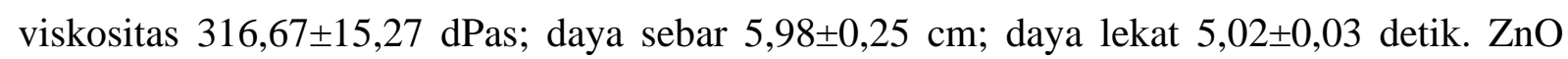
terdispersi ke dalam nanoemulgel memiliki kemampuan tabir surya secara in vitro dengan nilai SPF 25,0 (proteksi sedang) dan in vivodengan skor 1 (terjadi eritema sangat sedikit).

\section{Ucapan Terimakasih}

LPPM (Lembaga Penelitian dan Pengabdian Masyarakat) Universitas Sebelas Maret atas Hibah Dana Penelitian Mandiri Aktif.

\section{Deklarasi konflik kepentingan}

Semua author menyatakan bahwa tidak ada konflik kepentingan dalam penulisan naskah ini.

\section{Daftar Pustaka}

Basha, B.N., Prakasam, K., and Goli, D. (2011). Formulation and Evaluation of Gel Containing Fluconazole-Antifungal Agent. Int J Drug Dev Res, 3(4): 119- 127. 
Diba, R.F., Yasni, S., and Yuliani, S. (2014). Nanoemulsifikasi Spontan Ekstrak Jintan Hitam dan Karakteristik Produk Enkapsulasinya (Spontaneous Nanoemulsification of Black Cumin Extract and the Characteristics of Encapsulation Product). Jurnal Teknologi dan Industri Pangan, 25(2): 134

Gurning, H.E.T. (2016). Formulasi Sediaan Losio Dari Ekstrak Kulit Buah Nanas (Ananas Comosus L.(Merr)) Sebagai Tabir Surya. Pharmacon, 5(3): 2302- 2493.

Jafari, S.M. (Eds.), and McClements, D.J. (Eds.). (2018). Nanoemulsion: Formulation, Applications, and Characterization. Academic Press. UK.

Kaur, L.P., Garg, R., and Gupta, G.D. (2010). Development and Evaluation of Topical Gel of Minoxidil From Different Polymer Bases in Application of Alopecia. Int. J. Pharmacy and Pharm. Sci, 2(1): 43-47.

LMbanga. (2014). Sun Protection Factor of Cosmetic Formulation made in Kinshasa (DR Congo) by In Vitro Method Using UV-VIS Spectrophotometer. Departement de Chimie. Faculte des Sciences. Universite de Kinshasa. Democratic Republik of Congo.

Mahmoud, H., Al-Suwayeh, S., and Elkadi, S. (2013). Design and Optimization Of SelfNanoemulsifying Drug Delivery Systems of Simvastatin Aiming Dissolution Enhancement. African Journal of Pharmacy and Pharmacology, 7(22): 1482-1500.

Nugraheni, K. (2012). Pengaruh Pemberian Minyak Zaitun Ekstra Virgin Terhadap Profil Lipid Serum Tikus Putih (Rattus Norvegicus) Strain Sprague Dawley Hiperkolesterolemia. Skripsi. Fakultas Kedokteran Universitas Diponegoro, Semarang.

Nurahmanto, D., Mahrifah, I.R., Azis, R.F.N.I., and Rosyidi, V.A. (2017). Formulasi Sediaan Gel Dispersi Padat Ibuprofen: Studi Gelling Agent dan Senyawa Peningkat Penetrasi. Jurnal Ilmiah Manuntung, 3(1): 96-105.

Nurdianti, L., Aryani, R., and Indra, I. (2017). Formulasi dan Karakterisasi SNE (Self Nanoemulsion) Astaxanthin dari Haematococcus pluvialis sebagai Super Antioksidan Alami. Jurnal Sains Farmasi dan Klinis, 4(1): 36-42.

Niazi, S.K. (2009). Handbook of Pharmaceutical Manufacturing Formulations. CRC Press.

Niyogi, P., Raju, N.J., Reddy, P.G., and Rao, B.G. (2012). Formulation and Evaluation of Anti-inflammatory Activity of Solanum Pubescens Wild Extracts Gel on Albino Wistar Rats. International Journal of Pharmacy, 2(3): 484-490.

Kaur, L.P., Guleri, T.K. (2013). Topical gel: A Recent Approach for Novel Drug Delivery, Asian Journal of Biomedical and Pharmaceutical Science, 3(17):1-5.

Panjaitan, E.N., Saragih, A., and Purba, D. (2013). Formulasi Gel Dari Ekstrak Rimpang Jahe Merah (Zingiber Officinale Roscoe), Journal of Pharmaceutics and Pharmacology, 1(1): 9-20.

Patel, J., Patel, A., Raval, M., and Sheth, N. (2011). Formulation and Development of a SelfNanoemulsifying Drug Delivery System of Irbesartan. Journal of Advanced Pharmaceutical Technology and Research, 2(1): 9-15.

Pratiwi, L., Fudholi, A., Martien, R., and Pramono, S. (2017). Self-Nanoemulsifying Drug Delivery System (SNEDDS) for Topical Delivery of Mangosteen Peels (Garcinia Mangostana L.,): Formulation Design and In Vitro Studies. Journal of Young Pharmacists, 9(3).

Rowe, R.C., Sheskey, P.J., and Quinn, M.E. (2009). Handbook of Pharmaceutical Excipients, 6th Edition, Pharmaceutical Press, London.

Savale, K.S. (2015). A Review-Self Nanoemusifying Drug Delivery System (SNEDDS), International Journal of Research in Pharmaceutical and Nano Science, 4(6): 385-397.

Sayuti, N.A. (2015). Formulasi dan Uji Stabilitas Fisik Sediaan Gel Ekstrak Daun Ketepeng Cina (Cassia alata L.). Jurnal Kefarmasian Indonesia, 5(2): 74-82. 
Suena, N.M.D.S., Antari, N.P.U., and Cahyaningsih, E. (2017). Physical Quality Evaluation Of Body Butter Formulation From Etanol Extract Of Mangosteen (Garcinia Mangostana L.) Rind. Jurnal Ilmu Kefarmasian Indonesia, 15(1): 63-69.

Wulandari, S.S. (2017). Aktivitas Perlindungan Tabir Surya Secara In Vitro dan In Vivo dari Krim Ekstrak Etanol Daun Soyogik (Saurauia bracteosa DC). Pharmacon, 6(3).

Wulandari, W., Ermawati. E.D., Yugatama, A. (2019). Optimization SNEDDS (Self-Nano Emulsifying Drug Delivery System) of ZnO that dispersed into Hydrogel Matrix as UVProtective. IOP Conf. Series : Material Science and Engineering 578 (2019) 012058. International Conference on Advanced Material For Better Future 2018.

Yulianti, E., Adelsa, A., and Putri, A. (2016). Penentuan nilai SPF (Sun Protection Factor) Ekstrak Etanol 70\% Temu Mangga (Curcuma mangga) dan Krim Ekstrak Etanol 70\% Temu Mangga (Curcuma mangga) secara In Vitro Menggunakan Metode Spektrofotometri. Majalah Kesehatan FKUB, 2(1).

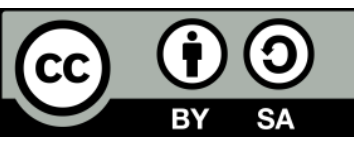

C 2020 by the authors. Submitted for possible open access publication under the terms and conditions of the Creative Commons Attribution-ShareAlike 4.0 International (CC BY-SA 4.0) license (https://creativecommons.org/licenses/by-sa/4.0/). 